\title{
Computerisation of primary care in Wales
}

\author{
John R Goves, Terry Davies, Terry Reilly
}

\begin{abstract}
Objective-To obtain information about the computerisation of general practice in Wales, and to enable more effective planning of educational provision for doctors and other primary health care workers.

Design-Postal questionnaire sent to all general practices in Wales.

Subjects -553 general practices, of which 401 (73\% replied).

Results - The level of computerisation varied from $11(85 \%)$ of practices in Powys Family Health Services Authority to $22(\mathbf{4 0 \%})$ in Mid Glamorgan. Less than half of practices had a computer in only two authorities. The commonest uses of the computer were for patient registration (208 practices), repeat prescribing (180), call and recall of patients (165), and partial clinical records (122). The main suppliers were VAMP (78 practices), AAH Meditel (46), and AMC (23). 102 of 226 practices with a computer had a terminal on each doctor's desk. Just 33 practices had full patient notes on computer and 51 had modems for electronic communication.
\end{abstract}

Conclusion-Mechanisms to encourage greater and more sophisticated use of computers and information technology need to be explored.

\section{Introduction}

The introduction of computers into general practices in Wales started to gather momentum only with the introduction of systems on the basis of a no cost option in return for providing prescribing data. More recently the government's scheme of partial reimbursement of computer costs has been introduced to increase computerisation.

The Department of Health surveys have not shown how well computers are being used. ${ }^{1}$ We conducted a survey of all the general medical practices in Wales to assess use of computers and attitudes and educational or other needs of both non-users and established users of medical computer systems. A full report of the survey's findings is available. ${ }^{2}$

\section{Subjects and methods}

We sent a postal questionnaire with an accompanying letter and return envelope through the family health services authority postal system to 553 general practices in Wales in 1990. After six weeks a further questionnaire was sent to all practices that had not replied.

The questionnaire was divided into four sections on two pages. The first section covered practice details such as the size and location of the practice and work patterns including training, dispensing, and branch surgeries. The second part explored attitudes towards electronic linkages with family health services authorities, hospitals, and drug information services. This section also asked about the future use of a practice computer for distance learning, decision support systems, and audit.

The third section was designed for practices that already had a computer. It asked detailed questions about their computer system, which included the date of installation; the type of hardware and software, together with details of any problems that had arisen; the current and intended use of the system; the details about the use of other software in the practice; the number of terminals being used now and planned in the future; the use of a communication device; and any intention to change the system hardware or software.

The final section was for practices without computers. It explored doctors' attitudes and intentions towards purchase and use of a computer in their practice. It also asked about their knowledge of the various systems available and their specific requirements for information and demonstrations of medical software systems. Users and non-users were asked about computer training needed by the doctors and other staff.

We collated the replies using the RBASE computer database system. Any queries that arose when we were entering data were clarified by a telephone call to the practice concerned.

\section{Results}

We received 401 completed questionnaires, giving a response rate of $73 \%$. This compared favourably with response rates in other postal surveys. The response rate by size of practice was sufficient to allow grossing up to represent all the practices in Wales. Where sampling variations existed in these strata standard errors were calculated with a $95 \%$ confidence that the true value lay within two standard errors of the estimate.

Since 1983 the growth in computerisation in primary care has been exponential, and the survey indicated that this growth rate would continue until 1992, by which time roughly $80 \%$ of practices will be computerised. Two hundred and twenty six practices already had computers and a further 103 intended to introduce them. We estimate that $67 \%$ of patients were served by a practice with a computer.

The level of computerisation was independent of whether the practice was rural, semi-rural, or in a town or city. Eighty per cent of training practices had computers. Of the computerised practices with branch surgeries, $98(92 \%)$ were not using their computer system at the branch surgery. The level of computerisation varied from $85 \%$ of practices in Powys Family Health Services Authority to $40 \%$ in Mid Glamorgan Family Health Services Authority. Mid Glamorgan and West Glamorgan were the only two authorities in which less than half the practices had computers

Most of the practices without computers were smaller than those with computers. Eighty five per cent (64) of practices with five or more partners were computerised, $70 \%$ (54) of practices with four partners, $60 \%$ (48) with three partners, and $36 \%$ (28) with two; $38 \%$ (33) of single handed practices had computers.

Eighteen types of proprietary medical software systems were in use in 193 practices. The four leading systems were VAMP (78 practices), Meditel (46), AMC (23), Update (12). All the other systems were used by less than 10 practices. Twenty four practices had developed their own computer software. Correspondence to:
Dr Goves.

BMF 1991;303:93-4 
Table I shows how computers are currently being used and the intended use among computerised practices. Table II shows the intended use in practices that are introducing computers. Table III gives the number of practices in each authority that have sufficient visual display units for each doctor, that have full patient notes on their computer, and that have communication devices (modems).

TABLE I-Current and intended use of computers in computerised practices

\begin{tabular}{lrcc}
\hline & $\begin{array}{c}\text { No }(\%) \\
\text { currently using } \\
\text { computer }\end{array}$ & $\begin{array}{c}\text { No intending } \\
\text { to use } \\
\text { computer in } \\
\text { future }\end{array}$ & $\begin{array}{c}\text { \% Lsing } \\
\text { computer } \\
\text { in future }\end{array}$ \\
Activity & $208(92$ & 6 & 94 \\
Patient registration (age and sex) & $122(54)$ & 42 & 72 \\
Clinical records-partial & $49(22)$ & 48 & 43 \\
Clinical records-full & $108(48)$ & 66 & 77 \\
Referral letters & $165(73)$ & 40 & 90 \\
Recall of patients & $94(4)$ & 65 & 70 \\
Audit & $180(79)$ & 27 & 91 \\
Repeat prescriptions & $114(50)$ & 45 & 70 \\
Practice reports & $42(19)$ & 82 & 55 \\
Accounts or wages & & & \\
\hline
\end{tabular}

TABLE II-Intended use of computers by 103 practices planning to computerise

\begin{tabular}{lrcc}
\hline & $\begin{array}{c}\text { No that will } \\
\text { Use computer }\end{array}$ use computer do & $\begin{array}{c}\text { No that do } \\
\text { not intend } \\
\text { to use } \\
\text { computer }\end{array}$ \\
Activity & 103 & & \\
\hline $\begin{array}{l}\text { Patient registration (age and sex) } \\
\text { Clinical records - partial }\end{array}$ & 55 & 2 & 20 \\
$\begin{array}{l}\text { Clinical records-full } \\
\text { Referral letters }\end{array}$ & 43 & 2 & 47 \\
Recall of patients & 96 & 7 & \\
Audit & 103 & 5 & 10 \\
Repeat prescriptions & 88 & 5 & 1 \\
Accounts and wages & 102 & 6 & 30 \\
\hline
\end{tabular}

TABI.E III-Practices with hest computer facilities by family health serivices authority

\begin{tabular}{lcccc}
\hline & & $\begin{array}{c}\text { No of practices } \\
\text { with a terminal } \\
\text { for each } \\
\text { consulting } \\
\text { room }\end{array}$ & $\begin{array}{c}\text { No of practices } \\
\text { with sufficient } \\
\text { terminals and } \\
\text { full notes on } \\
\text { computers }\end{array}$ & $\begin{array}{c}\text { No of } \\
\text { practices } \\
\text { with a } \\
\text { modem }\end{array}$ \\
\hline Authority & 74 & 14 & 6 & 6 \\
Clwyd & 73 & 15 & 5 & 10 \\
Dyfed & 94 & 16 & 4 & 12 \\
Gwent & 63 & 9 & 3 & 6 \\
Gwynedd & 101 & 14 & 8 & 1 \\
Mid Glamorgan & 18 & 2 & 3 & 6 \\
Powys & 75 & 18 & 4 & 10 \\
South Glamorgan & 75 & 14 & & \\
West Glamorgan & 64 & & & \\
\hline
\end{tabular}

\section{Discussion}

The government's decision to partially reimburse the costs of computers has not yet had a large effect on the rate of computerisation. Responses to our survey indicated that over $80 \%$ of responders will have computers by 1992 .

The reasons given for not having a computer were still the high cost and the increased workload. Smaller practices, which predominate in some parts of Wales, find these two aspects a particular problem. Such practices require increased reimbursement both for the system and for the additional staff costs. The increased workload associated with the new contract and the uncertainty about the future practice income have caused many practices to defer computerisation.
The full potential of a computer system is linked to the number of terminals available. The tasks that most of the currently installed systems are being used for can be undertaken in a back office or reception area. Just over a fifth of computerised practices had full clinical records on computer, and only a fifth stated that they intended to computerise records over the next few years. The concepts of having partial or full patient notes can be interpreted in different ways, and where possible we clarified what doctors meant by these terms.

Most of the practices with clinical records on computer and sufficient terminals had taken the no cost option from industry. The survey did not suggest that the current official reimbursement scheme was similarly encouraging full use of computers. To maintain full clinical records on computer, a terminal is required on each doctor's desk. This facility would also allow the development of interactive online systems for audit, decision support systems, and management by protocol. Information on prescribing and costs could also be made available.

Modem communications were also mostly found in practices that had taken the no cost option. Practices with branch surgeries holding patients' notes tended to have opted for networking through a dedicated Telecom land line. Many practices with branch surgeries have to consider this extra cost carefully when thinking about installing a system, and the decision has not been helped by the fact that the medical computing industry has until recently ignored communication problems in branch surgeries. Increased reimbursements to practices with branch surgeries in line with their communication needs should be considered.

The survey showed that nearly $90 \%$ of general practitioners wanted to be able to communicate electronically with family health services authorities, hospitals, and drug information services, although only $9 \%$ had modems. When data sharing through electronic communication becomes a reality the government should consider reimbursing the modem costs.

Until reimbursements are linked to computer use the scheme will encourage only expensive electronic organisation of simple tasks such as registration, repeat prescribing, and meeting targets. Only $6 \%$ of practices claimed to have full electronically held patient notes that could be used on line during consultations.

Some doctors, especially those with smaller lists, had succeeded in organising their practices manually and were reluctant to computerise. Smaller practices were still concerned about the capital and staffing costs.

Continuing education and audit is thought to be the way to improve patient care. Electronic clinical notes and communications will enable these processes to be more interactive in an everyday setting.

We thank all the doctors who replied to the questionnaire and the general managers of the family health services authorities for their help.

1 Statistics and Management Information Division, Department of Health. Computing survey 1990. London: $\mathrm{DoH}, 1989$.

2 Goves JR, Davies T. A survey of general medical practice computing in Wales 1990 Wales: Department of Postgraduate Studies, University of Wales College of Medicine, 1991. (ISBN 1873425015 .)

(Accepted 17 May 1991) 